\title{
BERTA BRASLASKY (1913-2008): UNA MAESTRA, LA ESCUELA DE LA VIDA Y LOS ITINERARIOS PARA TRAMITAR SU OBSESIÓN POR LA EDUCACIÓN
}

\author{
BERTA BRASLAVSKY (1913-2008): A TEACHER, THE SCHOOL OF LIFE \\ AND THE ITINERARIES TO PROCESS THEIR OBSESSION OF THE \\ EDUCATION
}

\author{
ANA DIAMANT \\ UNIVERSIDAD DE BUENOS AIRES \\ anadiama@gmail.com
}

\section{RESUMEN}

La historia de Berta, es la de alguien que se ha rebelado -junto a su familia y compañeros de ruta- a las circunstancias que hubieran obligado a un destino estrecho para argentinos no "predestinados" naturalmente a la escuela, a la que se sumaron socios de otras latitudes, algunos anfitriones de sus exilios, otros por la difusión de sus ideas, en la convicción de que la educación y sobre todo la lectura no son un derecho sino una garantía de inclusión.

La vida, la condición de estudiante y de graduada, la profesión, los viajes, las adscripciones ideológicas, la acercaron tanto a las luchas populares nacionales como a las ideas de circulación internacional y sobre todo, a las experiencias inspiradas en las utopías pedagógicas de la mano de Tolstoi y Makarenko, a las políticas de género desde su participación en 1948 en el I Congreso Internacional de Mujeres en Budapest, a la posibilidad de formarse en el Instituto de Psicobiología con Wallon, en hospitales europeos en los que conoce a Zazzo, Ajuriaguerra y Lebovici, a pensar en las diferencias de afrontar aprendizajes al tiempo que discutía la hegemonía médica en su tratamiento

Con sus testimonios y los de familiares, colegas, discípulos, se recorre casi todo el S $\mathrm{XX}$, desde los orígenes en una familia de inmigrantes judíos, el pasaje por la escuela rural, el traslado a la "gran" ciudad, la graduación como maestra, la actividad política y las persecuciones, la universidad, la formación de enseñantes, la gestión, siempre "militando" la alfabetización y la educación.

Desde Positivismo y Antipositivismo en Argentina (1952) pasando por La querella de los métodos (1962) hasta Primeras letras o primeras lecturas (2004) fortaleció la convicción de que no hay acto pedagógico aislado de su contexto y que las dificultades escolares deben ser una razón de estado. 


\title{
PALABRAS CLAVE
}

Testimonios; Educación; Aprendizaje; Alfabetización

\begin{abstract}
Berta's history, its from someone who has rebelled -with his family and fellow travelers - the circumstances that had forced a close destination for Argentines not "predestined" naturally to school, which partners joined from other regions, some hosts of their exile, others by spreading their ideas, in the conviction that education and especially reading are not only a right but a guarantee of inclusion.

The life, the student and graduate status, the profession, the travels, the ideological secondments, they approached to the national popular struggles and the ideas of international movement and especially the experiences inspired by the pedagogical utopias hand Tolstoi and Makarenko, to the gender policy since its participation in 1948 at the First International Congress of Women in Budapest, the opportunity to train at the Institute of Psychobiology with Wallon, in European hospitals where she know Zazzo, Ajuriaguerra and Lebovici, thinking about learning differences face while discussing the medical hegemony in treatment.

With their testimonies and those of family, colleagues, disciples, he runs most of the twentieth century, from its origins in a family of Jewish immigrants, the passage through the rural school, moving to the "big" city, graduation as a teacher, political activity and persecutions, college, training of teachers, management, always "militating" literacy and education.

From Positivismo y Antipositivismo en Argentina (1952) going to La querella de los método (1952) until The complaint methods (1962) to Primeras letras o primeras lecturas (2004) he strengthened the conviction that there is not an isolated teaching act and school difficulties must be a reason of State.
\end{abstract}

\section{KEY WORDS}

Testimonials; Education; Learning; Literacy 


\section{TESTIMONIOS Y CONTEXTO: MEMORIA, MEMORIAS Y UBICACIÓN DEL PERSONAJE ${ }^{1}$}

Volver sobre las complejidades de la memoria exige admitir que se trata de una materia que no es inmune al paso del tiempo. Y sí se trata de una formación que retorna sobre el pasado desde el presente [...] No hay condiciones para ejercicios de anticipación; nadie puede saber cómo será contada esta historia dentro de cincuenta años, entre otras cosas porque muchas de las apuestas arrojadas sobre el escenario de la transición siguen abiertas (Vezzetti, 2002, 191).

La recolección de narrativas referidas a la construcción de trayectorias, sean institucionales, identitarias o profesionales, pone en tensión versiones y situaciones, ya que generalmente se trata de usar relatos plurales para "levantar actas" de las múltiples facetas de un personaje. Es un acto político en tanto se adapta al punto de vista y a la actividad del sujeto biografiado y si bien se trata de una actividad singular en sus comienzos, conlleva procesos de identificación colectiva como resultado de la construcción de una imagen pública (Dosse, 2011).

Y esto es así porque los relatos no son neutros, son una matriz que, por su modo de producción, dan forma a una realidad, están gobernados por convenciones y convicciones, influyen en el modo de vivir luego de la emisión, trasuntan conflictos, articulan de alguna manera lo que se esperaba con lo que aconteció, son formas de sinceramiento con una particular estrategia retórica que suma a la vez texto e interpretación, tramando lo que ha sucedido, el modo de informarlo y dejando espacio, en la transmisión para otras maneras de interpretación (Olson et Torrance, 1995).

Los testimonios -informe sobre sí mismo- ya sean auto generados o a instancia de una interpelación, intentan mantener el pasado y el presente, en cierta forma, armónicamente unidos para el recuerdo, destacando que la relación entre historia y memoria es una preocupación central en el campo académico de las ciencias sociales (Jelín, 2002) y plantean una particular circunstancia epistemológica y psicológica que articula al yo que está

\footnotetext{
${ }^{1}$ Se han utilizado como base para esta presentación las entrevistas realizadas en 1993 por Ana Diamant y Nora Salles, filmada por Damián Zantleifer, en 2000 y 2001 por Ana Diamant, en su domicilio. También las realizadas en 2007 por Mariana Solanet y las que Nicolás Arata, Jesica Báez y Claudia Blanco publicaron en 2009.
} 
contando con los yo pasados acerca de los que se cuenta, así como una estrategia, que es hacer creíble la narración (Benveniste, 1971).

El lenguaje, que es a la vez recurso y contenido, pone una marca distintiva al relato, construye y reconstruye unas situaciones, urdiendo recuerdos del pasado, circunstancias vividas con posterioridad a los hechos narrados y coloca a la experiencia pasada frente al futuro dicha en un presente, creando mundos posibles -constructos- entre lo que se dice conocer y muchas veces lo que hubiera podido ser (Bruner, 2003).

En estos casos adquiere relevancia la posición que tanto al momento del suceso como al momento del relato ocupe el narrador en relación con el contexto - en las variantes entre éxito y derrota - en relación ya con lo épico, ya con lo nostálgico, entre las sensaciones de haber pertenecido e incidido o sentirse excluido.

\section{Cuando Berta dice}

con mucho orgullo me presento como Profesora Emérita de las universidades de Buenos Aires y La Plata. Esto es lo más importante. A pesar de que tengo otros méritos [...] pero siento como mayor logro el haber accedido a ser profesora emérita, por lo que es la Universidad de este país, por lo que ella ha significado en la historia de la educación y de la cultura [...]. Mi familia me orientó hacia la docencia [...]. Mis padres eran inmigrantes judíos de la Rusia zarista y habían expresado sus expectativas con respecto a sus hijos y yo debía ser maestra, como correspondía (B. B., 1993)

procura tanto verosimilitud como autoverosimilitud, en el juego de ciertas reglas globales y otras cruciales propias del género como los tiempos verbales, la alternancia entre verbos de estado y verbos de acción, las convenciones lingüísticas, y el eje en torno al cual se articulará el texto: la confianza, el amor, la búsqueda de una explicación, el prestigio, el deber como anclajes para ubicarse a sí misma en el mundo simbólico de la cultura con independencia (Olson y Torrance, 1995).

Con estas salvedades es posible reconstruir escenarios y posicionar actores con libretos propios que pueden variar en el tiempo extendido y aún en el transcurso de una misma entrevista, por efecto tanto de nuevas preguntas como de reelaboración de repuestas ya dadas, por impacto de las representaciones, que aun cuando idiosincráticas inciden en las experiencias y valoraciones compartidas, a instancias de los estilos comunicacionales, el confort del espacio de intercambio, la empatía entre entrevistador y 
entrevistado, los lugares ocupados y asignados, los significados potenciales atribuidos entonces y asignados hoy, reales o simbólicos, las fantasías y emociones, dimensiones esenciales para entender procesos historiográficos como el que se pretende abordar.

Si se entiende al texto del relato como una maniobra de ubicación, casi de navegación, de convertirse en miembro de un consenso, con la intención de

llevar un cargamento a un lugar concreto, $O$ se ubica a sí mismo para poder indicarles su posición a quienes deban rescatarlo en caso de que se rompa el mástil, se agote el combustible o se caiga una vela. Además [...] es reconfortante para uno, en tanto miembro de la especie humana, saber dónde está en relación con sus congéneres. (Sanders, en Olson y Torrance, 1995, 192),

muchas veces es necesaria una ayuda, parte de un acuerdo, y ese es el lugar del entrevistador, que ayude a elegir la ruta, los estilos, la profundidad de penetración en la memoria.

La particular relación entre historia y memoria y la específica naturaleza de ambas, puestas en contexto, impone que no exista ni una memoria ni un relato histórico sino que haya una constante batalla librada por diversas memorias que intentan contar historias y que una misma historia pueda ser contada una y otra vez.

Berta vuelve sobre su formación, en otro espacio y en otro tiempo, casi sobre el final de sus días, navega por otros mares con el mismo destino: ubicarse maestra:

Mis padres pensaban que yo iba a ser profesora. El mandato familiar para esa época era seguir el Magisterio, esa era la gran aspiración para una hija. Años antes, y es lo que le tocó a mi hermana, las hijas debían conformarse con una formación limitada. Recuerdo como si fuera hoy una escena: vivíamos en la primera casa en Buenos Aires, estábamos en la vereda con toda la familia y mi mamá le dijo a alguien: 'Ernesto va a ser abogado, Felipe contador y Berta va a ser profesora' Ya lo tenía pensado. De la pobre Anita que en ese tiempo iba a aprender a bordar con la Singer no dijo nada. Esa expectativa de mis padres que eran semianalfabetos en castellano, generaba que sus hijos se sintieran señalados como para cumplir con ese destino predeterminado. Antes era difícil rebelarse contra lo que los padres querían para uno (B. B., 2007).

Ambos testimonios son ella misma, son fragmentos de identidad que la sitúan en diferentes momentos vitales sobre la misma huella, son un imperativo de 
"domiciliación", la primera, más grandilocuente, la segunda, más íntima, ambas con deseos, con claroscuros, con presencia idiosincrática y con perspectiva social, con lógica compartida aunque no dicha de la misma manera.

Memoria, sujeto, comunidad y relato van ligados cuando se trata de la construcción de discursos y los resultantes - relatos en estos casos - son el juego de la interacción entre la cultura como producto social y por lo tanto compartido y el cultivo de la memoria. Son un modo de documentar y consolidar identidad (Achugar, 1999).

El transporte por los tiempos transcurridos, que son tiempos de hacerse y de revisar la hechura, ubican a quien cuenta en relación con sí mismo y con el sentido colectivo.

La recuperación del pasado dimensiona valores sociales compartidos y algún origen común, favorece la cohesión a la vez que refuerza las posiciones identitarias, delimita el campo de la propia vida, la separa y la une de la vida de los otros, hace sentido uniendo pasado y futuro

en una imagen comprensiva del proceso temporal. Es esa temporalidad la que modela el mundo humano y provee al 'yo' y al 'nosotros' de continuidad y consistencia, de coherencia interna (Florescano, 2012, 34).

Poder contar con la "traducción" de la oralidad al registro escrito, posibilita, contemplando todas las implicancias y arbitrariedades que esta maniobra contiene, revisar, reinterpretar y transformar el testimonio en objeto didáctico, en contenido de la enseñanza, con potencialidad y predisposición al "reuso". Volver al testimonio - escucharlo o leerlo - es ingresar a un campo de variaciones sorprendentes. Se ponen en tensión, además de los contenidos en su contexto de producción y de transmisión, los tiempos: el del acontecimiento y el del relato, mediados por el tiempo transcurrido y por las valoraciones que testigos y protagonistas hacen de los mismos hechos que narran.

También abre la posibilidad de discutir los alcances del texto narrativo como texto pedagógico y didáctico, como recurso para revisar y reposicionar acontecimientos y mensajes, para participar en la estructuración de identidades personales y profesionales, admitiendo que en el texto, cada narrador integrará la parte de la historia que ha resguardado por significativa, desechado aquella que por dolorosa o insatisfactoria puede producir angustia, 
constituyendo una nueva fuente de conocimiento. (Diamant y Cazas, 2013, $41)$.

Se trata de un objeto "residual" que ha sobrevivido a las maniobras de la memoria y de la reconversión de formato, de un "intertexto" de transferencia que hace de versiones vivenciales un material de enseñanza, que aporta formas de ser, de pensar, de actuar, culturas, aventuras, episodios y cronologías, legados de sentido, visiones del mundo, interpretaciones, relatos "contra culturales" que estructuran imaginarios individuales y compartidos, permitiendo que "viejas" ideas o experiencias, se transformen en "nuevos" contenidos.

\section{EL PERSONAJE SE CONSTRUYE A SÍ MISMO}

Había antes que otra cosa, una honda pasión por vivir. Un ardiente tributo que cobrar y pagar. Empezaba en los ojos, en las manos, danzaba en la luz, pero nunca sabíamos dónde terminaba. Fuerza viva que nos juntaba en la mañana para ver florecer el alba. La misma que nos ataba horas enteras alrededor de una disciplina de conocimiento cuando el interés se avivaba [...] Éramos una palabra dicha de día y en voz alta a nuestra conciencia, la razón de las cosas y los seres (Jesualdo, 1960, 23).

Desde la experiencia infantil de haber sido "activista" tesorera en la cooperativa de su escuela primaria en el interior de la provincia de Entre Ríos para garantizar que la revista Billiken llegara regularmente y que a ella pudieran acceder sus compañeros, pasando por sus acciones nacionales e internacionales - algunas elegidas, otras promovidas por anfitriones diversos y otras obligadas por el exilio político - hasta la sus campañas inclaudicables por el derecho a la lectura y la escritura, tanto en democracia como en dictadura, hay un itinerario que, cual hilo de Ariadna, recorre anécdotas, formación y militancia con carácter genético e ininterrumpido.

Es evidente que me remito a la historia antigua, como corresponde a mi edad. Siempre digo que viví durante todo el siglo ya que nací en 1913 y algunos historiadores señalan que el siglo XX nace en 1914, con la Primera Guerra Mundial (B. B., 2009).

Son dos los caminos posibles para "resumir" a Berta, el de la secuencia impactante de sus logros y el de la valoración de cada uno de ellos en la perspectiva del contexto espacio temporal en el que se desarrollaron. Ambos se potencian entre sí, junto a los testimonios de la protagonistas, sus 
contemporáneos, familiares y seguidores, componen la figura que recorre la escuela, la política y la vida concreta del Siglo XX.

El historial de vida cuenta que su familia, conformada por inmigrantes judíos, perseguidos desde la Rusia zarista se instala, después de breves estadías en zonas cercanas, en Sola, Departamento de Tala, Provincia de Entre Ríos

Mi padre vino al país con toda la familia: su madre, su padre, cuatro hermanos varones y cuatro o cinco hermanas mujeres. Llegaron a fines del S XIX, en el segundo barco de inmigrantes judíos, el mismo que también traía a los hermanos Enrique y Adolfo Dickman que luego fueron diputados, y a Alberto Gerchunoff Todos fueron a parar a las colonias de Entre Ríos. Mi madre llegó más tarde, a principios del S XX, convocada por una hermana que había venido a la colonización de Moisés Ville [...] [Se conocieron en Buenos Aires] por casamenteros, que era el método que había entre los judíos (B. B., 2007).

La familia se traslada a Buenos Aires en 1922, entre otras cosas, para garantizar que su interés por la escuela pudiese materializarse en un título de maestra, que recibe, con medalla de oro en 1930 en la Escuela Normal $N^{\circ}$ 7, en pleno auge de la Década Infame.

Llegamos acá, donde conocimos las penurias económicas. Y los traslados [...] Con mis hermanos siempre comentábamos que, a pesar de tanto trajinar, y los intentos de mi padre por lograr una mejora económica, nunca fuimos ricos. Mi padre no supo hacer fortuna [...] Nosotros, aunque no pasábamos necesidad, teníamos que ser austeros. Recuerdo que mi hermano Felipe caminaba la ciudad entera para ahorrarse pagar el tranvía que costaba 10 centavos (B. B., 2007).

La medalla de oro no fue, como esperaba, un pase directo al campo laboral, al que pudo ingresar con mucha dificultad, tiempo después, a instancias de las gestiones que realizara el Inspector Pablo Pizzurno, particularmente sensible a la situación de los inmigrantes. Con esta primera batalla ganada, comienza una larga sucesión de enfrentamientos y alianzas que la acompañarían hasta el final de sus días (Pineau, 2014).

Yo soy Maestra Normal Nacional, egresada de la escuela José María Torres de Buenos Aires, cuyos directores y docentes, egresados directos de la Escuela Normal de Paraná, fueron Olegario Maldonado y Victoria García. Yo me recibí de maestra allí [...] Creo haber recibido una formación pedagógica muy seria y muy nueva [...] todo esto del constructivismo como gran novedad, en contra de la escuela tradicional, estaba para nosotros muy presente: la actividad del niño y su producción. Nuestras prácticas en la escuela estaban 
orientadas a que fuera el niño el que elaboraba el conocimiento y se nos evaluaba en la medida que lo lográbamos (B. B., 1993).

En 1933 retoma los estudios superiores en el Instituto Nacional Superior del Profesorado Joaquín V. Gonzalez, en la carrera de Física, admitiendo, tiempo después, que, si bien no tenía "nada que ver conmigo" consideraba que el futuro estaba en ese campo científico (Diamant, 1996).

Ingresé en momentos de gran entusiasmo por la Física y de ideologización de las Ciencias Exactas, cuando cundían las experiencias de Einstein o de Marie Curie. No era para nada mi carrera, aunque la cursé íntegra y dignamente. Pero no la pude terminar porque me exoneraron cuando sólo me faltaba rendir dos materias que ya había cursado. Eso sucedió en el Instituto Nacional del Profesorado 'Joaquín V. González'. A fines de 1936, por orden del Ministro Jorge De la Torre, con su decreto contra la creación de los centros de estudiantes (B. B., 2009).

En ese trayecto, se involucra definitivamente con la militancia estudiantil y política de izquierda y toma estrecho contacto con quien ella misma señala como su primer maestro: Aníbal Ponce (1898-1938). Estos hechos, en el contexto de época que se vivía hacen que fuera expulsada junto a Ponce por el Ministro Jorge de la Torre, quien en un informe leído en sesión de la Cámara de Diputados, denunciaba sus actividades extremistas.

Cuenta ella misma que este hecho tuvo dos implicancias potentes. La primera, una profunda depresión que motivó que su familia la trasladara a la Ciudad de Córdoba . La segunda, superada esta situación, la intención de volver a estudiar.

Cuando me expulsaron del Profesorado, con el gran conflicto interno del socialmente 'expulsado' me refugié en la casa de unos parientes de Lázaro Braslavsky, que ya era mi novio, en las sierras de Córdoba. Estando allí, leí la noticia de la creación de la carrera de Pedagogía. Le escribí a mi hermana para que me inscribiera, y así fue que llegué (B. B., 2007).

Comienza un nuevo desafío, que culmina con un Diploma de Honor, en un momento particular de la historia de la filosofía y de la educación. Son tiempos de tensión entre espiritualistas e idealistas con positivistas y racionalistas, todas concepciones que no encontraron apoyo en Berta.

Su tesis de graduación, sobre la recepción de la filosofía enciclopedista en el Río de la Plata, es un estudio original tanto desde el punto de vista del 
contenido como de la perspectiva teórico-metodológica, sobre todo si se tiene en cuenta que fue escrita durante la primera mitad del siglo XX. En ella destaca la presencia de las ideas de Rousseau en el Río de la Plata, la de la teoría de la riqueza de las naciones, a través de Moreno y Belgrano y las derivaciones que tuvieron en la concepción de Educación Popular, forjada durante el siglo XIX (Arata, 2012).

En 1943, encara un nuevo proyecto polémico, la creación del IAR - Instituto Argentino de Reeducación, cuando en el país, por una parte el estado no garantizaba el funcionamiento de centros especializados para la atención en Pedagogía Terapéutica o Asistencial y por otra, significaba una oportunidad de enfrentar a la hegemonía médica en la atención a los problemas de aprendizaje o de desarrollo que eran objetivos fundacionales:

chicos que no se adaptaban [...] podríamos ahora decir chicos diferentes. Esa era nuestra idea, pero en la práctica no había mucha madurez en el medio social para acudir a especialistas en dificultades de aprendizaje. Por otra parte, había necesidad de establecimientos de otro tipo, para chicos más severos y comenzamos a aceptar y a recibir un poco lo que venía, y de acuerdo con eso el equipo fue organizándose y comenzamos a adaptar nuestra actividad a los casos que llegaban. Aparecíamos como algo de avanzada. De Francia había traído todos los elementos para el diagnóstico y para la educación (B. B., 1993).

Para la formación de los profesionales que allí se desempeñaron, se valió en parte de experiencias autodidactas, en parte de bibliografía llegada del exterior, uniendo la medicina, la psicología y la pedagogía a lo que le fue sumando su propia experiencia en el exterior, cuando aún no existía en la Universidad de Buenos Aires la Carrera de Psicología, por lo que esta institución puede considerarse un antecedente fundacional de la misma.

En el IAR confluyeron, además de una decisión reparatoria, acciones asistenciales, de formación de agentes vinculados a la docencia y a la atención de niños con necesidades especiales.

Promoví la creación de un instituto privado [...] Al no poder ejercer en ninguna institución pública necesitaba generar un lugar de aprendizaje privado. El instituto estaba destinado a chicos con problemas sensoriales, mentales, corporales, pero fueron a parar prácticamente todos los chicos con debilidad mental o los que padecían oligofrenias. De modo que puesta en la tarea de crear el instituto, convoqué a algunos compañeros de la facultad para que trabajaran conmigo [...]. Muchos eran profesionales vinculados al Partido 
[Comunista] y de mucha calidad profesional. En cuanto a la orientación del Instituto, era medio difusa, estaba de moda el tema de la conducta, pero la verdad, es que no sabíamos exactamente qué queríamos hacer. A mí me interesaba la educación aplicada a problemas específicos que se generaban por razones naturales, o digamos biológico-químicas (B. B., 2007).

Fue uno de los primeros establecimientos dedicados a la atención de las deficiencias mentales y llegó a albergar hasta 200 alumnos procedentes de la Argentina y de países limítrofes, muchos de ellos provenientes de sectores populares, cuando pudieron establecerse convenios con las obras sociales. El objetivo fundacional era difuso: tratar los problemas de aprendizaje, de aquellos niños que no se adaptaban a la escuela común, que de alguna manera se diferenciaban en su desarrollo, con limitaciones que obligaban a la elaboración de planes de estudio que no solamente contemplen el plafond de edad que estos niños podían alcanzar y su ritmo lento de desarrollo, sino que además contuvieran técnicas especiales que ayudaran a corregir esos problemas y otros asociados.

Interesé al Dr. Peluffo en la creación de ese instituto (... " "El asunto fue así: yo tenía relaciones de amistad y político estudiantiles con los Machinandearena, gente de gran poder económico pero con un sentido progresista: en Mar del Plata habían mejorado la rambla, el casino, el Hotel Provincial. El caso es que uno de los hijos era dirigente estudiantil en la Facultad de Derecho y yo estaba en la FUA [...] les propuse que nos apoyaran financieramente y darle participación a una hermanita y aceptó. Primero hablé con la hermana mayor, Delia. La conocía porque había actuado en la Junta de la Victoria, una organización de lucha en contra del racismo, a favor de la democracia" (B. B., 1993).

Con la sanción de la ley de Enseñanza Privada, en la época del primer peronismo, comienza a recibir aportes que permiten subvencionar alumnos internos y externos y profundizar los conceptos y las técnicas psicopedagógicas para el tratamiento de las dislexias caracterizadas entonces como un síndrome que se refiere a una dificultad que afecta solamente la adquisición de la lectura en niños que son inteligentes y que, por lo menos hasta cierto momento de su evolución escolar, son capaces de realizar los otros aprendizajes, así como estudios sobre la evolución de la lectura y del grafismo en la primera infancia (Prudhommeau, 1956).

Desde el año 1944 habíamos ensayado el método global, el método de palabras generadoras, la combinación de ambos métodos y ciertas prescripciones de la escuela de Winetka que aconsejan enseñar primero una cantidad determinada de palabras para iniciar después el análisis de las mismas, realizando 
físicamente, a veces, con la tijera actuando sobre tiras de papel. Desde 1957 empezamos a interesarnos por los elementos motores que intervienen en el aprendizaje de la lectura (B. B., 1993).

Estos avances fueron posibles por la formación adquirida en Francia, entre 1948 y 1949 en el Instituto de Psicobiología del niño, bajo la dirección de Henry Wallon y en contacto directo con Prudhommeau, cuyas baterías instrumentales adaptó y utilizó con éxito no sólo en el caso de disléxicos, sino de deficientes mentales en general, colaborando sobre todo con la consideración que sobre los primeros tenían los maestros de escuela común, abriendo camino a través de la ortopedagogía o pedagogía correctiva, difundiendo la idea de que

el caso de los disléxicos merece pues reflexión [...] el maestro tiende a atribuirlo a un estado general de ininteligencia, error que puede tener consecuencias graves y tiende a marcar al niño alterando sus posibilidades de reacción saludables[...] Habiendo elegido la especialidad de la pedagogía correctiva y como nos consagráramos a la educación de los débiles mentales, hacia el año 1944 iniciamos nuestro trabajo siguiendo, para enseñarles a leer, las prescripciones aconsejadas por la literatura clásica. Los resultados no fueron satisfactorios...adquirimos puntos de vista nuevos, aumentamos nuestra información sobre la psicología del aprendizaje en general y encontramos otros instrumentos para satisfacer las exigencias de nuestro propio trabajo [...]la actividad que se despliega en el consultorio externo de nuestro Instituto nos permitió igualmente elaborar un juicio sobre la enseñanza de la lectura en general, además de la experiencia que acumulamos sobre la enseñanza de la lectura a los débiles mentales (Braslavky, 1962, 121).

Con la difusión de la ideología de la educación común, ingresan al sistema escolar niños que manifiestan la imposibilidad de seguir el ritmo, de adaptarse a los intereses o de aceptar los métodos y la disciplina de trabajo que sigue la mayoría. Las estadísticas francesas y los estudios posteriores realizados por Braslavsky en este medio demuestraron que aquellos niños, con supuestas deficiencias e inadaptaciones, constituían un número importante de la matrícula escolar, y que con excepción de los "ineducables", entre el 1 o el 2 $\%$, eran susceptibles de mejorar, tal como lo planteaba la pedagogía correctiva y ya no diferencial como se la nominaba, y es como finalmente se caracteriza a la actividad desarrollada por el área pedagógica del IAR: la normalización de los niños para que puedan integrarse a la vida corriente (Braslavky, 1962). 
La actividad creció no sólo en relación con los niños, también con los docentes que concurrían por cientos a los cursos de verano a la Escuela Superior, con la investigación, la organización escolar diferencial, la atención higiénica y sanitaria y la fiscalización de los resultados, al tiempo que Berta ya

había empezado mi actividad en la Universidad, de manera que tenía otra organización del tiempo, trabajando menos en el instituto y entonces fui perdiendo el control. Mucho más cuando me tuve que ir del país. Allí perdí no sólo el control académico sino también el económico. Entonces no pude disfrutar de lo que había creado porque fui totalmente desplazada y llegamos al punto en que tuve que pedir la intervención judicial. Cuando en los estrados de la justicia se me pidió que justificara pedagógicamente las razones por las que pedía el cierre, dije que en su momento había sido creado de acuerdo a concepciones de la época, pero que después se había desvirtuado (B. B., 1993).

Cuando en 1948 participa en Budapest del Primer Congreso Internacional de Mujeres por la Paz como delegada de la Unión de Mujeres Argentinas (UMA),

había representantes de todo el mundo, entre ellas también diputadas francesas. Entonces yo les manifesté mi interés de por ir al Instituto de Psicobiología del Niño dirigido por Henry Wallon. Ellas me ayudaron, de manera que viajé a París inmediatamente. Al día siguiente tuve una entrevista con Wallon. Él me orientó hacia su secretaria [...] que me organizó todo el trabajo durante mi estadía en París [...] organizó mi participación en los cursos de Wallon y de otros. En aquel momento estaba Piereau que actuaba en el College de France [...] Zazzo, Canderie y Prodhommeau que era el pedagogo del equipo [...] así tuve oportunidad de ver todo lo que se hacía en París (B. B., 1993).

Para entonces, y en los años subsiguientes, la militancia política y pedagógica de Berta se alinea en una tradición progresista, sustentada por militantes comunistas, que dio en llamarse el jacobinismo, en concordancia, seguramente, con algunos planteos expresos en su tesis de graduación -en la que discute la influencia de la Revolución Francesa en la Revolución de Mayo - que destaca el impacto de la inmigración - su propia historia - frente a la imagen esencialista y homogénea de nación que proponían las posturas liberales (Puiggrós, 1997).

En la universidad, se discuten cuestiones políticas, técnicas y curriculares que se tocan con las posturas desarrollistas, de renovación educativa, de revisión de los postulados de la escuela nueva tradicional hacia la escuela nueva con sesgos politécnicos, con clara influencia de la pedagogía soviética, en la que se 
destaca el valor del trabajo, las conductas socialmente valoradas y la relación entre la escuela y la vida

normas, convenciones, ciertos saludos, símbolos, todos aspectos que le daban organicidad al complejo educativo, y donde se reconocía la autoridad del maestro. Recordemos que verdaderas tribus juveniles recorrían como parias los caminos de Europa. Recuperar principios menos laxos [...] era un hecho histórico importante en la pedagogía de esa época. Una vez me tocó concurrir a un acto histórico. Fue un acontecimiento que se organizó para la Navidad en Bellville [...] Nunca me voy a olvidar. Las tribunas estaban todas colmadas de niños huérfanos de las Maisons des Enfants, fue conmovedor. Hubo un gran discurso de uno de los líderes del PCF que habló para esas criaturas solitarias que lo escuchaban desde las gradas. Les dijo quiénes habían sido sus padres, y el papel histórico que habían jugado en la guerra. Se estimulaba en esos chicos un cuerpo de ideas y concepciones contra la guerra. El mensaje era claramente a favor de la paz y por un mundo mejor (B. B., 2007).

Los años 50 no sólo la llevan a Berta nuevamente a la Universidad, también a acompañar proyectos fundantes de educación no formal en el ámbito de la colectividad judeo progresista laica. Allí participa tanto de la formación de docentes idiomáticos para las escuelas idishistas del ICUF como de la consolidación del proyecto pedagógico de la colonia Zumerland.

La colonia ya estaba funcionando cuando me invitaron a discutir sobre sus objetivos y funciones. Ya no se trataba de concurrir a las clases que se dictaban algunas tardes en las escuelas, sino de intervenir en el diseño de un proyecto de largo alcance. Un proyecto aparentemente limitado a algunas decenas, quizás centenas de niños y jóvenes que pasarían sus vacaciones al aire libre. Pero, en el espíritu de los iniciadores existía tanto sentido y tanta imagen de trascendencia, que todo era poco para cumplir con sus expectativas. Eran momentos de grandes acontecimientos en la historia, de grandes debates en la política, en las ideas y en las conciencias. En pedagogía, tenían gran prestigio las ideas pedagógicas inspiradas en las utopías sociales desde las de Tolstoi hasta las de Makarenko [...] Allí veíamos de qué manera actuaban los maestros a través de acciones cotidianas que ponían en práctica los principios de autogestión, de convivencia, de solidaridad asentadas en la base de la responsabilidad personal y colectiva (B. B., 2000).

La vida universitaria la convoca como docente, tanto en Buenos Aires como en La Plata.

A la primera ingresa en 1957, cuando 
los estudiantes estaban pidiendo cátedras [paralelas] [...] cuando llega Salas a la Facultad, se abren las cátedras paralelas. Entonces yo me presento, Ahí hubo un jurado muy interesante: Ghioldi y Telma Reca. Hicimos el coloquio. Se presentaron bastantes aspirantes. Klimovsky y yo entre ellos [...] No era una revancha sino una posibilidad de acceso. Era paralela a la de Tobar García [...] entretanto los estudiantes seguían pidiendo que yo ingresara a la Facultad ante cualquier vacío que había (B. B., 1993).

A la Universidad Nacional de La Plata llega

cuando ganó Illia y me llamó por teléfono Ricardo Nassif [...] 'La Profesora Córsico se va a Inglaterra y queremos que usted tome la cátedra'. Era la cátedra de Psicología Educacional. Yo le dije: 'no sé nada de Psicología Educacional'. El caso es que armé un programa a mi manera y resultó muy bueno [...] La experiencia en La Plata fue una maravilla y al año siguiente se hace el concurso para Educación Diferencial y gané con el acuerdo de todos. Entonces me llamaron de la Universidad de Buenos Aires. Y así empezó mi carrera docente [universitaria]. Yo ya tenía cincuenta años. Siempre le digo a la gente que se considera vieja, que yo me inicié a los cincuenta (B. B., 1993).

Desde entonces, desde múltiples plataformas -atravesadas por persecuciones y exilios- desde diversas posiciones académicas y profesionales, aún antes de la publicación de La escuela puede, Berta no deja de pensar que puede y que debe dar la batalla por aproximarse a a una distribución igualitaria de la alfabetización, a pesar de la heterogeneidad real en el punto de partida, cuando desde fines del siglo XVIII hasta los comienzos del presente la escuela viene siendo impotente en su objetivo de la difusión de la lengua escrita y la formación de lectores, refractaria a modificar las causas de la deserción y la repitencia, que en gran parte dan lugar a las variantes del analfabetismo y a la abundancia de los "no lectores" (Braslavsky, 1991).

La publicación de La Querella de los métodos en la enseñanza de la lectura. Sus fundamentos psicológicos y la renovación actual (1962) marca el ingreso de Berta al mundo de la producción académica. Desde entonces, hasta su última publicación, Adquisición inicial de la lectura y la escritura en escuelas para la diversidad (2006) siguió impulsando para que la escuela dé la gran pelea por la lectura comprensiva, siguió denunciando que su falta es un fenómeno que preocupa tanto como el analfabetismo, siguió pregonando que hay que enseñar a leer y que aprenderlo requiere un esfuerzo, siguió haciendo propuestas pedagógicas, pensando cambios con el supuesto básico de que no hay acto educativo aislado de un contexto y que la resolución de la crisis de los procesos de aprendizaje debería ser una razón de Estado. 
Llegaron tiempos de cesantías, exilios personales y familiares

en el '75, cuando exoneraron a todos, mi hija Silvia era Titular en Río Cuarto y Cecilia era ayudante de carrera de Ciencias Sociales. La familia entera salió de la Universidad de entonces. Nos dispersamos [...] en el '75 con la segunda sangría producida desde arriba, se hicieron exoneraciones (B. B., 1993).

La perspectiva familiar dolorosa y traumática, descripta por su hija menor, Cecilia da cuenta de exilios, desarraigos y reencuentros con el retorno a la democracia:

Es así [...] cuando asume el Ministerio de Cultura y Educación Ivanisevich [...] me echan a mí de la Universidad Nacional de Río Cuarto, la echan a mi madre de la Universidad Nacional de La Plata y las Tres A amenazan a mi hermana que era Profesora Titular en la Universidad Nacional de Río Cuarto. Mi hermana tenía dos hijas, yo no tenía hijos en ese momento y nos vinimos las dos a vivir a la casa de mi madre [viuda desde 1954 ]. Vivimos todas juntas [...] En ese momento uno era parte de una historia, de los avatares que atravesaba un grupo muy importante de la sociedad argentina [...] la sacamos bastante barata. En mi familia no hubo muertos ni desaparecidos (B. B., 1996).

El 12 de abril de 2004 fue incorporada a la Academia Educación. Entonces manifestó que hubiera querido ocupar el sillón de Juana Manso - que ya tenía destinatario - tomó el que lleva el nombre de Bernardino Rivadavia y eligió dar cuenta de su decisión. Disertó ante un salón desbordado de colegas, discípulos, colaboradores, amigos y familiares sobre el Desarrollo natural y desarrollo cultural en la educación. Enseñó una vez más.

Esta multifacética mujer, encuentra su síntesis en la presentación que de ella hace un colega cuando la propone correligionaria en defensa de los derechos humanos, compañera en la lucha por la paz, la justicia y el trabajo, camarada de la utopía y de la vida, cofirmante de las solicitadas contra la marginación y la pobreza, militante por la extensión de las oportunidades de acceso a la educación, asociada en la difusión de la lectura y la escritura, miembro plena de la defensa de la alegría (Cucuzza, 1996, 11).

\section{BERTA, LA MUJER QUE SE COMPONE Y SE CONTIENE A SÍ MISMA}

Un espacio biográfico como reservorio de las formas diversas en que las vidas humanas se narran y circulan, si bien sugerente, no alcanza para delinear un 
campo conceptual [...] El espacio biográfico así entendido - confluencia de múltiples formas, géneros y horizontes de expectativa - supone un interesante campo de indagación (Arfuch, 2002, 49).

Hacer de la vida de Berta un itinerario es la oportunidad de recorrer la historia de vida de una mujer, una maestra, una activista, una académica, casi sin lugares comunes, atravesando la génesis familiar, la construcción de su propio núcleo, la militancia legal y clandestina, la producción intelectual, la docencia, la estadía en la escuela a la que concurrió hasta casi el último día de su vida.

Para cada una de estas "paradas" de su larga vida, algunas frustrantes, otras muy estimulantes, Berta tiene algo que decir. Por eso elegimos la perspectiva testimonial para recuperarlas. "Asumo mi condición, mi edad. No me importa mostrarme como estoy. Yo tengo para esto la misma franqueza que para todas las cosas: para expresar mis posiciones personales, afectivas, políticas" (B. B., 1996).

Y todo esto rescatando aquellos hechos, que más allá de lo anecdótico hicieron puntos de inflexión en la historia de la educación argentina del siglo $\mathrm{XX}$, que lo atravesó casi por completo, plasmando ideas en acciones:

Yo llegué a la carrera de Ciencias de la Educación, pero desde mi puesto de maestra, entré a Filosofía desde mi barrio, y a la larga creo que este viaje [...] se convierte en una metáfora de un viaje entre la cultura oral popular y la cultura letrada de las elites, un viaje en el que finalmente no termino de pertenecer a ninguna de las paradas (B. B., 2007).

Pensar a Berta en clave de legado hace que circulen imágenes construidas a partir de entrevistas a las que se prestó con entusiasmo y generosidad, por las que desfilaron personas, tiempos, lugares, instituciones, actos, ideas, ideología, todas plasmadas en hechos que dejaron -o dejarán-impronta en la escuela, y en todas se trasunta un componente militante y una experiencia de vida militante que la antecedía, que se internó en ella, seguramente desde las vivencias más primarias aprendidas de sus padres -compartidas con sus hermanos- migrantes judíos socialistas de la Europa Central, que llegaron como tantos otros a las colonias de Entre Ríos escapando de la hambruna, donde Berta hizo sus primeros grados y libró su primer batalla militante, la de la cooperativa Billiken, de la que fue tesorera a instancias de su maestra; experiencia que como dijo Cecilia, su hija menor, fue una puerta para acceder la cultura letrada de su tiempo. 
Dada la demanda creciente desarrollada al ritmo de la incorporación de la mujer, era muy difícil ingresar a la Escuela Normal. Lo conseguí a costa de perder dos años, pero con mucha dedicación, egresé de la misma con medalla de oro [...] Me tocó recibirla y agradecerla en nombre de todas, en una ceremonia que se hizo en el teatro Cervantes, donde se agruparon cuatro generaciones. Aún con ese promedio, para el que me había esforzado tanto, no había posibilidades de trabajo en la ciudad y ni mi familia ni yo misma aceptábamos mi reclusión en una de las escuelas rurales alejadas que se ofrecían (B. B., 2009).

Y desde entonces no paró nunca. Ni cuando pensó que la medalla de oro obtenida en el Normal $N^{\circ} 7$ iba a ser un pasaporte al cargo de maestra para el que se había preparado, y no fue así. Ni cuando fue exonerada, por su militancia estudiantil, de su condición de alumna del Profesorado de Física y siendo una jovencita enfrentó a la prensa, los actos públicos solidarios que en su caso llegaron a la cámara de diputados.

Ingresé al profesorado en Física y ahí intervine en las luchas estudiantiles. Eran los años 31 - 32, justamente cuando llegó Jorge de la Torre al Ministerio [...] fui separada del profesorado. El primero que reaccionó fue el Partido Socialista. Fuimos a la Casa del Pueblo, me atendió Nicolás Repetto personalmente, lo llamó a Juan Antonio Solari, que era el director de La Vanguardia para que me hicieran una nota [...] El rector del Profesorado, Traquia, se negó a suspenderme en la matrícula, como lo ordenaba el Ministro. Fue un gran demócrata y a la vez el que introdujo las orientaciones espiritualistas en Filosofía. Traquia como compensación lo exoneró a Aníbal Ponce como profesor de Psicología de la Infancia. A partir de ahí Ponce se fue del país. En ese momento yo cortaba mi carrera a punto de terminar. Realmente una profunda depresión. Además la interpelación parlamentaria fue terrible. Jorge de la Torre llegó a decir en la Cámara de Diputados que no era por política sino por otras cosas que no podía decir para no herir los oídos de los señores diputados. Eso apareció en La Prensa. Imagínese lo que significó para mí. Me deprimí mucho (B. B., 1993).

Volvió a estudiar, ya no Física, sino Pedagogía y se sumó a las actividades de las agrupaciones universitarias reformistas, "visitaba" con frecuencia en su condición de detenida por militancia la Sección Especial de la Policía contra el comunismo.

Tuve que interceder mil veces, en todas las oportunidades en que, por cualquier cosa, salía a la calle y la metían presa en la comisaría de la calle Urquiza 850 que era el reducto de la Sección Especial contra el Comunismo (E.P., 1993). 
Junto a su esposo Lázaro participó de las campañas en solidaridad con la República española, con las tropas aliadas, contra el nazi fascismo.

Conocí a Lázaro en 1934 [...] Cuando nos encontramos por primera vez yo estaba terminando la Escuela Normal [...] Mientras yo estaba en el comunismo, él militaba en defensa de los derechos de los judíos [...] porque habían sido víctimas de los progroms [...] Era el tesorero y el representante de las organizaciones judías en la FOARE [Federación de Organismos de Ayuda a la República Española] A mi casa solían venir los intelectuales que pasaban por Buenos Aires [...] había todo un movimiento de intelectuales que visitaba el país, desde Pablo Neruda hasta Rafael Alberti [...] Lázaro tenía un laboratorio especialmente dedicado a elaborar medicamentos para los combatientes de la República [...] Tengo una fotografía junto al barco que llevaba el cargamento (B. B., 2007).

Como estudiante universitaria,

yo estaba prohibida, había tenido mucha intervención social y política desde que egresé de la Escuela Normal [...] En el año 1932 yo andaba por los patios de la escuela mientras los aviones del golpe de estado del 30 tiraban volantes" (B. B., 1993)

Cuando no pudo trabajar en el estado como resultado de la persecución ideológica y debió "inventarse" un lugar privado, el IAR fue su refugio a la vez una reacción a la falta de respuestas por parte del estado al tema de las necesidades especiales y diferentes:

lo empezamos en el 43-44. Entonces todavía encabezaban estas funciones [psico pedagógicas] médicos psiquiatras [...] Mi marido y yo éramos amigos del Dr. Julio Peluffo y lo interesamos en la creación de este instituto. Teníamos psicólogos como Isolda Breyer y Rapella - que habían seguido Filosofía porque en ese momento no existía la Carrera de Psicología, pero tenían interés y se especializaban en psicología - además estábamos Elena Dukelsky -también egresada de Filosofía- y yo - egresada de Pedagogía (B. B., 1993).

Su primer viaje a Europa fue

en el año 1948. En Budapest se hizo el Primer Congreso Internacional de Mujeres y fui como delegada de una agrupación cultural femenina. Se trabajaba con la UMA, visitamos a Victoria Ocampo para interesarla. Fueron las dos organizaciones que mandaron delegadas a ese congreso por la paz, después de la guerra. Había representantes de todo el mundo, entre ellas unas diputadas francesas [...] Era el tiempo del auge del tema del fracaso escolar y 
en particular de las dislexias. Por ese motivo concurría al Hospital André Rousselle donde trabajaba Zazzo con Ajuriaguerra. También estuve el Hospital de San Juan Malades donde estaba Lebovici y tuve oportunidad de presenciar las reuniones que hacía con los chicos después de una entrevista individual. Así pude ver, por ejemplo, el psicodrama que estaba en su gran momento [...] Otra de las cosas fundamentales que recuerdo fue la visita a la Maisson des enfants donde vi cómo se trabajaba escolarmente con chicos con dificultades [...] Todo era muy sacrificado, estaba en un hotel, me pagaba todo por mis medios (B. B., 1993).

La puesta en práctica de los nuevos enfoques, algunos traídos del viajes, otros creados, otro resultados de la hibridación ente teoría y práctica, encontraron en el IAR,

el primer lugar donde estuve aplicando todo [...] Al volver me invitó a su casa Serebrinsky que trabajaba con Bernstein en La Plata para exponer lo que había visto. Allí tenían el Instituto de Psicología [...] Todo ocurría fuera de los ámbitos oficiales en los que estaba prohibida. Sin embargo hice una gran difusión [...] Eran conocimientos de avanzada. Acá nadie hablaba de las dislexias, era inédito. $\mathrm{Y}$ en el instituto empezamos a trabajar con disléxicos (B. B., 1993).

La docencia universitaria y las actividades de consultoría internacional, iniciadas según ella misma describe, en forma tardía, después de los cincuenta años, igualmente dejaron tiempo para experiencias más que intensas:

Participé en la renuncia del 66 [en la UBA]. Fue una audacia colectiva. Pero el cuerpo docente de La Plata decidió permanecer y allí me uní a ellos [...] Del año 70, tengo una anécdota interesante. Había sido convocada por UNESCO para hacer misiones en los países de América Central. En el período de la ley antidemocrática, me había mantenido en la Universidad de La Plata, pero todo el mundo estaba afuera. Llegó el momento en que me aplicaron a mí la ley antidemocrática y le mandaron al rector la orden de que me suspendiera. Él me llamó y me mostró la orden que venía de la SIDE . La rompió y me dijo que no la iba a obedecer y que yo seguiría trabajando, cosa que ocurrió. Seguí en la Universidad de La Plata mientras que judicialmente tenía un proceso. La defensa del abogado era que yo podía tener mis ideas políticas - que eso estaba fuera de cuestión - pero que cumplía y que no ejercía ninguna presión sobre los estudiantes [...]Entretanto la UNESCO me convoca nada menos que para una misión en Cuba, pero yo estaba bajo proceso. Lo consulté con el abogado: No le puedo aconsejar que vaya, pero si yo estuviera en su lugar, iría. Y fui. Trabajé 3 meses. Fue una gran experiencia, interesantísima desde todo punto de vista. Incluso por las críticas que hice a algunas de las acciones que tomaba el gobierno [...] En ese momento acá se discutía una de las grandes reformas en 
educación. Esos sucesivos proyectos de reforma que tendían a disminuir el nivel de la enseñanza pública. Primero había sido la de Astigueta. Ahora era la del ministro Cantini [...] Curiosamente me llamó el rector y me dijo que desde el gobierno nacional querían una definición de la Universidad de La Plata [...] Nos convocó a mí, que estaba en contra de la reforma y a otro profesor, cuyo nombre no interesa, que la defendía [...] Y se produjo una Asamblea Universitaria. Yo siempre bajo proceso. Esto da una idea de cómo eran las cosas en la vida universitaria [...] Algunos amigos me decían que no tuviera confianza, que ese rector iba a tomar la medida cuando menos lo esperara. Y yo tuve confianza. El caso es que hicimos la asamblea y se votó. Salió a 8 columnas en el diario El Día y a 5 en el diario La Nación de Buenos Aires y al día siguiente cayó el ministro Cantini [...] El gobierno necesitaba una definición porque había una movilización en contra de esa reforma (B. B., 1993).

Los exilios, las cesantías, los retornos y la reincorporación, ya la encontraron grande, pero no por eso sin fuerzas, con zozobras y gratificaciones:

Vuelvo del exilio en el año 79 y me encuentro con una periodista, Lena Burtin y me hace una entrevista por teléfono a raíz de ciertas informaciones del Director General de la UNESCO que sostenía que estaba aumentando el analfabetismo en el mundo. Me pidió opinión. Yo le dije: '¡Cómo no va a aumentar si en nuestro país se estaba enseñando a leer con métodos prehistóricos!' Ella lo publicó. El Secretario de Educación, Prof. Michilo, la llamó y le pidió una entrevista. Ella con cierta alarma me pidió que la acompañara y fuimos juntas. Estaba todo su equipo y me pidió que explicara por qué había dicho eso. Después de la entrevista me invitó a que participara con ellos. Le pedí que me dejara pensarlo. Deseaba aceptarlo como un desafío, pero era la época de la dictadura. Empecé a consultarlo con todos mis amigos. Me decían que aceptara, que me tenían confianza. Entonces puse una condición: que me dejaran ir a las aulas. Aceptaron y pusieron a mi disposición un auto y dos personas que me acompañaban. Fue una experiencia riquísima. Acumulé muchas anécdotas [...] En una oportunidad asistí a una clase dada por una maestra mayor. Aparentemente una clase brillante que terminó con el pedido a los chicos de que dijeran oraciones. Al día siguiente yo también les pedí oraciones. Uno de ellos dijo: Daniela me tomó la limonada. Le pregunté: “¿En el desayuno? ¿Tomás limonada en el desayuno?" Como los chicos quedaron mudos, escribí en el pizarrón: no me gusta la leche. Les pedí que lo leyeran. Los chicos miraron a la maestra porque todavía no les había enseñado ni la "g" ni la "ch". A pesar de eso, todos lo leyeron. Porque lo aprendieron del medio [...] Les enseñaban las 9 letras que tienen correspondencia directa en el español. Además la "y" para la palabra yo y para la conjunción. La "s" sólo para los plurales. Estaba prohibida la palabra sopa. El fundamento era 
foniátrico, para evitar las dislexias y para evitar las faltas de ortografía. (B. B., 1993).

Hay mucho más. La significación de una trayectoria nunca es unívoca ni puede ser saturada. Hay más anécdotas para resignificar, más lugares para recorrer, más familia por conocer, más relatos para interpretar, más personajes para interpelar, más espacios para visitar, más... más mujer, más maestra, más militante, más académica, todos sentidos de una vida, como los que se presentaron.

Hasta acá, retornos sucesivos, progresivos del sujeto y sobre el sujeto. Hay otros itinerarios, siempre evocaciones distanciadoras y reveladoras de una singularidad. Nada definitorio ni definitivo, biogroafemas, informaciones, explicaciones que escapan al canon acostumbrado para un ensayo, que nunca son exhaustivos, que a diferencia de la imagen o del texto "cerrado" no se cristalizan aunque la forma permanece fiel a cierta deconstrucción, el retorno sobre uno mismo, la exposición de sus afectos, de sus recuerdos, la imagen de sus familiares $[\ldots]$ el retorno de lo reprimido (Dosse, 2011).

\section{CONCLUSIÓN SOBRE EL PERSONAJE Y SOBRE LA FORMA DE HISTORIARLA}

Al recurrir a la memoria como fuente documental (...) debemos estar atentos a sus múltiples dimensiones cognitivas. En ese aspecto, no se debe olvidar que la memoria oral es una reconstrucción desde el presente, en el que el narrador recuerda algo vivido. Sin embargo, aquello que él dice haber vivido no necesariamente ocurrió de la forma narrada. (Torres Montenegro, 2014, 29)

Testimoniar y buscar el testimonio es un intento de constituir una matriz a partir de la cual los acontecimientos narrados adquieran sentidos y lógicas. Lo que se cuenta, y el modo en que se cuenta, hacen a un intento de mantener aceptablemente unidos lo acontecido y lo posible, de consolidar identidad, de evidenciar tensiones entre memoria e historia y entre dimensiones y hechos (Diamant, 2010), entre descubrimientos y encubrimientos.

Con estas maniobras, hoy Berta queda reconocida y discutida por su tarea docente en todos los niveles del sistema educativo, por sus investigaciones, por las acciones de formación, por su tarea de difusión internacional, por la originalidad de sus ideas, por sus trascendentes aportes a la didáctica, por la confianza en la función de la escuela, por la batalla por despatologizar la 
educación especial, por sus principios sobre la normalización e integración de la educación.

\section{REFERENCIAS BIBLIOGRÁFICAS}

Achugar, H. (1999). El lugar de la memoria. A propósito de los monumentos (Motivos y paréntesis). en Martín Barbero, J y otros, Cultura y globalización, Santa Fé de Bogotá. Edición Universidad Nacional de Colombia.

Arata, N. (2012). Algunos comentarios a la tesis de B. Braslavsky. Buenos Aires. Inédito.

Arata, N., Ayuso, M. L., Baez, J. y Díaz Villa, G. (2009). La trama común. Memorias sobre la carrera de Ciencias de la Educación. Buenos Aires: Editorial Facultad de Filosofía y Letras.

Arfuch, L. (2002). El espacio biográfico. Dilemas de la subjetividad contemporánea. Buenos Aires: Fondo de Cultura Económica.

Benveniste, E. (1971). Problems in general linguistic. Miami: University of Miami Press Coral Gables.

Braslavsky, B. (2014). La querella de los métodos en la enseñanza de la lectura. Buenos Aires: UNIPE Editorial Universitaria.

Braslavky, B. (1991). La escuela puede: una perspectiva didáctica. Buenos Aires: Aique Grupo Editor.

Braslavky, B. (1962). La querella de los métodos en la enseñanza de la lectura. Buenos Aires: Kapelusz.

Bruner, J. (2003). La fábrica de historias. Derecho, literatura, vida. Buenos Aires: Fondo de Cultura Económica.

Cucuzza, R. (1996). Presentación. En Berta P. de Braslavsky. Maestra, Profesora, Militante, Humanista. Buenos Aires: Facultad de Psicología, Secretaría de Cultura y Bienestar Universitario.

Diamant, A. y Cazas, F. (2013). No me acuerdo...Cómo fue que aprendí a enseñar Psicología. Buenos Aires, Memorias. V Congreso Internacional de Investigación y práctica Profesional en Psicología. Universidad de Buenos Aires.

Diamant, A. (2010). Testimonios de enseñar y aprender. Ser Psicólogo en la $U B A$ de los 6 . Buenos Aires: Teseo.

Diamant, A. (2002). Berta Braslavsky y el Instituto Argentino de Reeducación. La reposición de una información casi perdida. Buenos Aires, Memorias IX Jornadas de Investigación. Buenos Aires: Facultad de Psicología, Universidad de Buenos Aires. 
Diamant, A. y col. (1996). Berta P. De Braslavsky. Maestra, Profesora,

Militante, Humanista. Buenos Aires: Facultad de Psicología, Secretaría de Cultura y Bienestar Universitario.

Dosse, F. (2011). El arte de la biografía. México: Universidad Iberoamericana. Florescano, E. (2012). La función social de la historia. México: Fondo de Cultura Económica.

Jelin, E. (2002). Los trabajos de la memoria. Madrid: Siglo XXI de España Editores.

Jesualdo (1960). Fuera de la escuela. Buenos Aires: Ediciones Meridion.

Olson, D. y Torrance, N. (1995). Cultura escrita y oralidad. Barcelona: Gedisa.

Pineau, P. (2014). Berta P. de Braslavsky: la utopía de alfabetizar a todos en la escuela, en La querella de los métodos en la enseñanza de la lectura. Buenos Aires: UNIPE Editorial Universitaria.

Prudhommeau, M. (1956). Les classes de perfectionnement. La raison, 16.

Puiggrós, A. (Dir) (1997). Historia de la Educación Argentina VIII.

Dictaduras y utopías en la historia reciente de la educación argentina (1955 - 1983). Buenos Aires: Galerna.

Solanet, M. (2008). Braslavsky. La educación achica las diferencias. Buenos Aires: Capital Intelectual.

Torres Montenegro, A. (2014). Recorridos historiográficos y metodológicos de la contemporaneidad. En Historia, Voces y Memoria. Revista del Programa de Historia Oral. Buenos Aires: Instituto Interdisciplinario de Estudios e Investigaciones de América Latina.

Vezzetti, H. (2002). Pasado y presente. Guerra, dictadura y sociedad en la Argentina. Buenos Aires: Siglo XXI Editores Argentina. 